\title{
Seeing Data, Feeling Data: The Visual Language of Numbers in Mona Chalabi's Instagram Infographics
}

\section{Fatma Shahin}

\section{Abstract:}

In this paper, I explore the work of data journalist Mona Chalabi, whose data visualizations on Instagram represent a confluence of art, data, and online multimedia. Through her data visualizations, Chalabi makes use of the affordances of Instagram-its audience, its format, its interactivity-to bring to light various critical statistics about social justice issues. In bringing together Instagram and data journalism, Chalabi's data visualizations embody a bold and unique way of enacting digital social justice activism.

\section{Keywords:}

data visualizations (DVs), Instagram, data journalism, social justice, activism

DOI: 10.33137/ijournal.v6i2.36455

(C) 2021, Shahin, F. Mary Leslie: Seeing Data, Feeling Data: The Visual Language of Numbers in Mona Chalabi's Instagram Infographics. This is an Open Access article distributed under CC-BY. (c) (i) 
Mona Chalabi is a data journalist whose work operates at the intersection of two unlikely actors: Instagram and data journalism. Her posts are a confluence of art, data, and multimedia elements that come together to facilitate a unique kind of social justice activism. Seeing as her work derives its impact from Instagram (@monachalabi), especially considering her 437,000 followers (Chalabi, n.d.), it becomes important to explore the work and the platform in tandem to unravel their cooperations. For if Instagram enables the creation of "visual social media cultures" that, in turn, act as a "conduit for communication" (Leaver, Highfield, \& Abidin, 2020, p. 1), then Chalabi's data visualizations are one example of what possibilities lie within such cultures. By examining Instagram's "gestalt" (Cara, 2019, p. 335), its content and its contexts, one can begin to understand the multilayered operation of Chalabi's data visualizations.

\section{Data Visualizations}

\section{What is a Data Visualization?}

Data, today, is akin to air: one inhales clicks and scrolls, exhales ads and cookies. Needless to say, data are inextricable from "our worlds and our experiences of living in them" (Pinney, 2020 , p. 224). In a time where data proliferates, data visualization offers an avenue for understanding its operation, particularly when it comes to political issues.

A data visualization (DV) is a visual representation of data that is two-pronged in that it is "created to amplify the cognitive processing" of the data as well as to facilitate its social application (Engebretsen \& Weber, 2017, p. 278). As media, DVs are "abstractions and reductions of the world," molded by the subjectivities directing those abstractions and reductions (Kennedy \& Engebretsen, 2020, p. 22). Despite their state as abstractions, however, the social applications of DVs are far from abstract.

\section{Data Visualizations and Instagram}

Data visualizations and Instagram are unlikely, but complementary, media. They are both “plural technologies" (Cantón-Correa, 2020, p. 1696), multimodal "super-genres” (Aiello, 2020, p. 49) with "innovative semiotic forms" that enable "novel types of communication and interactivity" (Kennedy \& Engebretsen, 2020, p. 20). In the already multimodal environment of Instagram - a platform that, like the DV, is grounded in visuality and "aesthetic visual communication" (Manovich, 2017, p. 41) - the interactive and communicative capacities of DVs become all the more prominent. In a "culture of visualization" (Aiello, 2020, p. 50) where the visual resounds, DVs and Instagram come to embody two media through which to examine the role and impact of 
the visual. Mona Chalabi's Instagram account exemplifies one way in which to mobilize the polysemic aspects of both these media to foster a new, distinct form of data social justice activism.

\section{What Data Visualizations Do}

\section{A Social Semiotic Approach}

In this discussion, I take a social semiotic approach to unravel the workings of DVs, particularly as they manifest in Chalabi's Instagram account. A social semiotic approach "relates texts to contexts to reflect on the social and political implications of meaning-making" (Aiello, 2020, p. 50). Such an approach lends itself to DVs, especially Chalabi's, as it allows one to explore how "the 'rules' of sign-making may be broken or changed," consequently allowing for "semiotic innovation" that is conducive to social change (Aiello, 2020, p. 50).

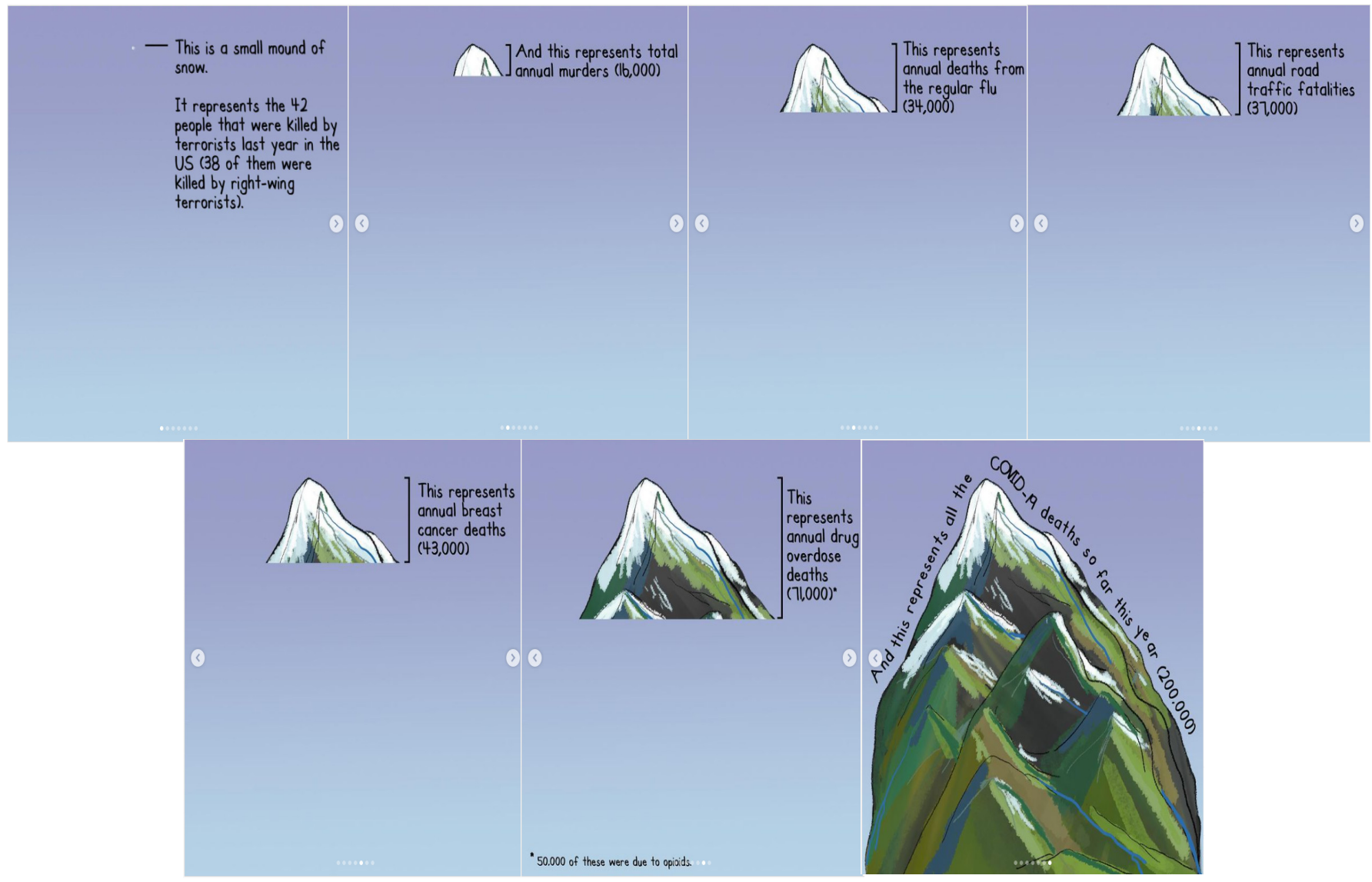

Figure 1. From left to right, the seven images that the user swipes through in Chalabi's post to get to the final image depicting the death toll of COVID-19 in the United States (in the first seven months of the pandemic). 
Take, for instance, Chalabi's Instagram post about COVID-19 deaths in 2020 (Chalabi, 2020, September 22) (fig. 1). The post is not, strictly speaking, a "typical" DV: it does not feature bars or $\mathrm{X}$ and $\mathrm{Y}$ axes. But as the user swipes through the post's images, the data becomes clear and so, too, do its implications. The final image of the post is a powerful visual representation of what 200,000 American deaths from COVID-19 look like. To that end, the post operates on various levels of signification: it depicts data on its own in each individual image, but also data in relation to other data through the series of images that one swipes through. It is this juxtaposition of absolute and relative which ultimately clinches the post's semiotic purpose when the user reaches its final image, a representation of the immense death toll of COVID-19. Rather than opt for a conventional DV, Chalabi depicts her data in the form of a mountain, and it is this semiotic innovation that allows her to deliver her message all the more potently. The mountain is not just an analogue for the number of deaths. Rather, it is monumental, and its scale is imposing - data becomes material because it has material consequences; it looms large.

\section{The Aesthetics of Data Visualization}

Aesthetics is not typically a primary concern of a semiotic approach, but it is essential to a social semiotic one (Burn \& Kress, 2018, p. 18), and all the more so to DVs, which are aesthetic in nature. As Burn and Kress (2018) put it, if "style is the semiotic toolkit of identity," then "aesthetics is the discursive taste regime surrounding it" (p. 15). That is, issues of aesthetics are always ideologically laden, and in the case of Chalabi's work, they are explicitly ideological. Chalabi's aesthetic does not exist without politics because her aesthetic is her politics: her DVs are always saying something about social justice issues by way of her artistic style.

One can see this at play in a post wherein she depicts the Americans who were either not counted or double-counted in the 2010 census (Chalabi, 2020, February 27) (fig. 2). The DV depicts its statistics in the form of a pencil, with the eraser representing the Americans who were not counted, and the pencil itself those who were doubled-counted. Stylistically, the image of the pencil is used to concretely visualize how people of colour, especially Black Americans, are literally erased from surveys that are meant to represent them. Chalabi often literalizes the subject matter of the data she depicts in this way to work against the abstraction inherent in DVs. But more broadly, Chalabi's style contributes to her overarching aesthetic: all her DVs are digitally plotted and then hand-drawn. As Chalabi herself says, "On a computer, data looks slick. I draw over it to show that data isn't always precise" (Gagne, 2020). In effect, Chalabi demonstrates that the DV that can be traced back to a subjectivity - to the hand that created it - is in many ways more trustworthy than the DV that is not because it is more methodologically transparent. Indeed, 
the fact that her DVs are on Instagram to begin with, as opposed to a more "official" outlet like a news website, already tells us much about how she works to situate data on the level of the individual, whether it be the person drawing the DV or the person encountering it on their Instagram feed. Such is Chalabi's "semiotic toolkit," one with which she builds the ideological foundations of her posts.

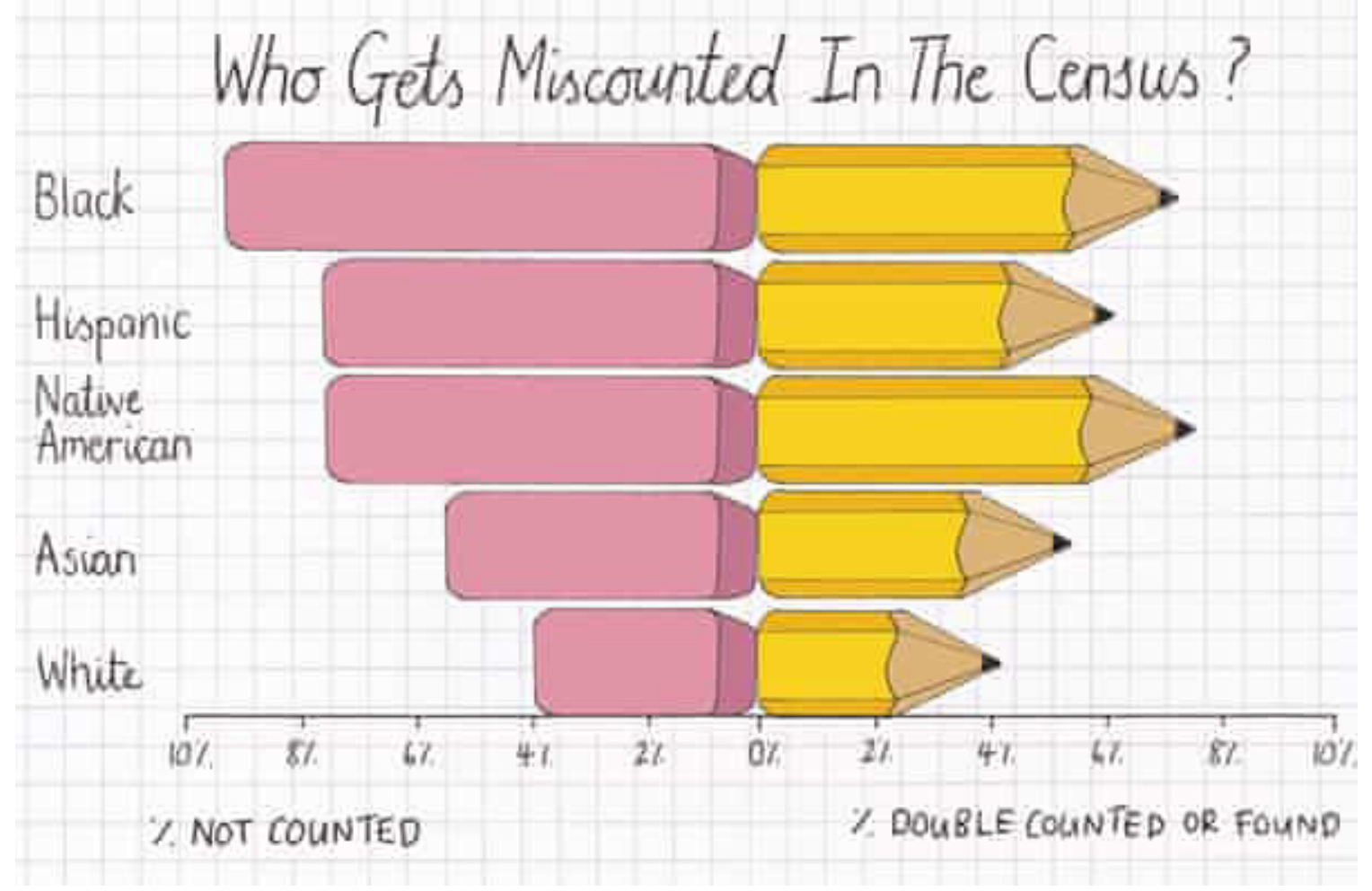

Figure 2. Chalabi's data visualization depicting the percentage of Americans, by race, who were miscounted - either not counted or double-counted - in the 2010 census.

\section{Data Visualizations on Instagram: \#BlackLivesMatter and Black Disenfranchisement}

\section{Data Journalism as Storytelling}

Chalabi’s DVs are "art with a function” (Cantón-Correa, 2020, p. 1696), drawing and elaborating on the medium's storytelling capacities to foster an activist digital space. As such, the power of the DV lies not in the data, but in its storytelling capacities at the hands of a storyteller. Chalabi's field, data journalism, is time and again characterized as a form of storytelling: it is a "set of . . . approaches to storytelling" (Gray, Chambers, \& Bounegru, 2012, p. 6), "a story whose primary source ... is numeric (rather than anecdotal)" (Knight, 2015, p. 59), "a process" that eventually "links to a narrative" (Veglis \& Bratsas, 2017, p. 111). But Chalabi's data journalism iJournal, Vol 6, No. 2, 
is not just storytelling - it is visual storytelling. Accordingly, it easily carves a space for itself on Instagram, a selfsame "place of visual storytelling" (Cara, 2019, p. 349). What kind of narratives, then, arise from the enmeshing of these two media? Chalabi's DVs about \#BlackLivesMatter and anti-Black racism are one example of what these narratives might look like in action.

\section{Eschewing the Distance of Objectivity}

A story cannot be indifferent; it always says something. Likewise, Chalabi's DVs are stories in that they always say something, and say it clearly and unabashedly. To that end, Chalabi's work eschews any notion of objectivity by resisting hegemonic notions of data as neutral or self-evident. Instead, Chalabi underscores "the politics and epistemology of partial perspectives" (Haraway, 1988, p. 583), treating data as a "situated knowledge" (Haraway, 1988, p. 581) such that in her hands, it becomes subjective and political, political because it is subjective. As stories, Chalabi's DVs exemplify this repudiation of objectivity through their concomitant repudiation of distance. For objectivity bears a kind of apartness; it describes, but it does not participate. The distance of that apartness is significant as it inheres in the DV: when people, objects, and spaces are reduced to numbers, then aggregated into a graph, "our distance from them increases. We interpret them as separate from us" (Rettberg, 2020, p. 37). And this is, in some ways, essential to how the ostensible objectivity of data works: the "use of a data visualization . . carries with it a rhetorical weight," it says, "look, we have data. This is true" (Rettberg, 2020, p. 39). To Chalabi, however, a DV cannot allow for objectivity because it should not allow for distance. If DVs are two-pronged in their function, then Chalabi's show that they must also be two-pronged in their action: does the reader feel as well as understand the data and its implications?

To counter such notions of the so-called objectivity of data, Chalabi enacts a form of storytelling that is bold and explicitly not objective. In one post, she frames the British criminal justice system as a game, a race that a Black and white boy are running separately (Chalabi, 2020, June 5) (fig. 3). Through a series of images that the user swipes through, Chalabi reveals statistics about the obstacles that the Black boy disproportionately faces compared to his white counterpart. Critically, these statistics come in the form of bars (as in a bar graph) that act as literal obstacles to the Black boy. By the end of the post, the Black boy is impeded by four bars that represent statistics about systemic factors "stacked against" him. The post is a story, each swipe through its images revealing a new narrative point, all of which converge towards a message that is supported by the visual framing of the post: "This is a system that plays with people's lives and black Brits continually lose the game." The image of "stacked" obstacles, of Black lives treated as playthings within the criminal justice system, is a narrative one: it is a metaphor drawn in data rather than data masiJournal, Vol 6, No. 2, 
querading as its own self-evident, "objective" image. But even more so, it is a metaphor grounded in the material realities of navigating the criminal justice system as a Black British boy.

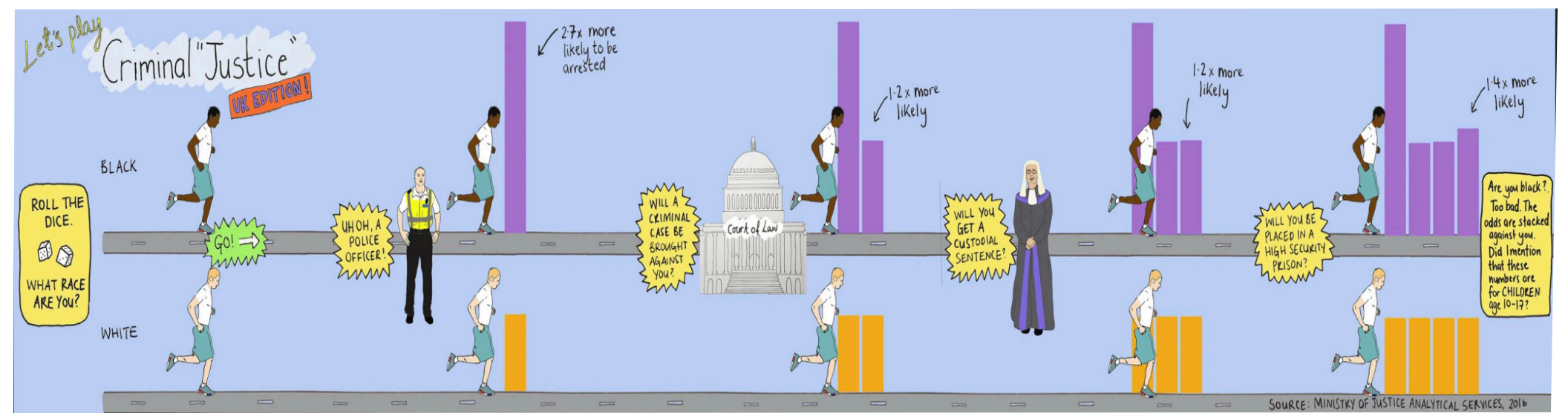

Figure 3. From left to right, the five images in Chalabi's post depicting various statistics that pertain to the experiences of Black British boys in the criminal justice system.

\section{The Emotion in (and of) Data}

In an interview, Chalabi remarks, "I don't even pretend to be objective ... Hiding behind objectivity feels like negligence" (Gagne, 2020). One way in which Chalabi exposes the farce of objectivity is by using emotion as the main "epistemic resource" of her work, making it "a way of knowing that is valuable for building a critique of the world" (Kennedy \& Engebretsen, 2020, p. 24; Jaggar, 1989), in this case a social justice critique. Chalabi continues, "If you're looking at sentencing by race across the criminal justice system ... for example, you should feel emotional. You should feel pissed off!" (Maitland, 2020). To her, data, particularly when it deals with marginalization, has a moral and ethical responsibility to not be objective, but rather to provoke emotion and, hopefully, incite activist action.

Consider one post in which Chalabi compares the percentage of American police officers who received a conviction for killing someone, a charge but no conviction, or no charges at all (Chalabi, 2020, May 30) (fig. 4). The extent of the first two is immediately visible as $0.3 \%$ and $1.0 \%$, respectively, but the user must swipe a staggering nine times through the post's images to get to the end of the visualization. There, they finally see that $98.7 \%$ of killings by police officers "resulted in no charges whatsoever." The effect of the post is sobering, and it is precisely that sobering quality which is its "epistemic resource." 
Figure 4. From left to right, the ten images the user swipes through in Chalabi's post about American police officers who killed someone and consequently received a conviction, a charge but no conviction, or no charges whatsoever.

A social semiotic reading of the post reveals how it accomplishes its political purposes through its presentation on Instagram. To be sure, the post is interactive, explicitly telling the user to "keep swiping" to reveal the full extent of the DV's data. But interactivity, here, is not simply about technical input from the user, nor is it a mere means to the end of getting to the data in that final image. Instead, the swiping communicates a phenomenology of data. In this post, data is not simply viewed, it is experienced: one swipes once, twice, three times through the post's images, and still the data has not materialized-how long will this go on? After nine swipes, the user experiences a kind of "...oh" reaction, the product of feeling the impact of the data as well as understanding it.

The splitting of the data into ten images is functional for a DV: it conveys the disproportionality of one statistic in the dataset. In the case of this post, however, it also bears a spatial function. Again and again one swipes through the images, and again and again one is troubled to see another image telling one to "keep swiping..." Herein Chalabi's decision to split the data potently conveys its scale; in being presented in discrete parts, the post communicates a wholeness that would not have otherwise been possible: indeed, the percentage of officers who received "no charges whatsoever" is so big, so disproportional, that it cannot, should not, be presented in one image. To make her DV work, Chalabi makes the user work, enabling a cognitive understanding of the data as well as an emotional and experiential connection to its sociopolitical ramifications with regard to \#BlackLivesMatter and police brutality.

\section{Reciprocal Storytelling}

But to tell a story is also to tell it to someone. How are the "readers" of Chalabi's posts invited into her data storytelling practices? Chalabi's work is unique in that it uses the image-cen- 
tric, interactive affordances of Instagram to enable a "dialogical conversation rather than a oneway lecture" (Lewis, Holton, \& Coddington, 2013, p. 231). Her storytelling, then, is reciprocal, relying on interaction from the viewer in order to enact its effects.

In one post, Chalabi combines storytelling with interactivity to encourage her followers to support Black-owned businesses during the COVID-19 pandemic (Chalabi, 2020, June 1) (fig. 5). The post features an illustration of various buildings and sites along a street. As the user swipes through the post's images, they encounter data about Black-owned businesses that have had to shut down due to the pandemic, but also about Black-owned businesses in various sectors that are still open. In the caption, Chalabi encourages users to tag their favourite Black-owned businesses in the comments, businesses which she then tags in the images themselves. And so the post comes to embody a kind of alliance of contributions from both Chalabi and her followers. It ultimately becomes, as Chalabi writes, "a resource that you can bookmark and return to" to find out about, and support, Black-owned businesses. In this way, Chalabi presents a scene and her followers respond, in turn, to "populate" and enliven it. Such is the life of the Instagram post that is open rather than closed, dynamic rather than static.

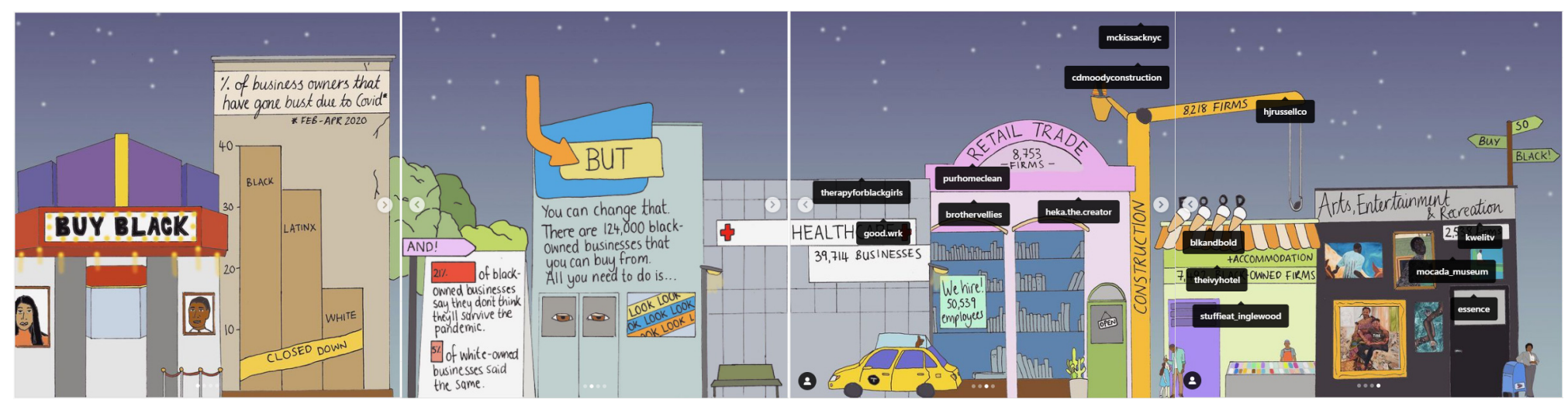

Figure 5. From left to right, the four images in Chalabi's post depicting various statistics about Black-owned businesses during the COVID-19 pandemic. Of note are the third and fourth images, in which Chalabi has tagged the Black-owned businesses that users have suggested to her in the post's comments. In this way, Chalabi embeds commenters' contributions into her original post.

\section{Conclusion}

If, as Stephen Spencer (2011) writes, "we are visual beings in a world which is a visual array of meaning" (p. 1), then DVs are one way to understand that world. By mobilizing their visuality, Chalabi creates a language for these DVs that uses storytelling, emotion, and interactivity to highlight the politics of data. In Chalabi's work, data need not "speak for itself" because Chalabi iJournal, Vol 6, No. 2, 
has already articulated it so well: she has created a visual language with which it can speak, and speak resoundingly. Her DVs say: this is the data, these are the people it affects, and this is why you should care. Altogether, Chalabi's DVs are perhaps best encapsulated by a line from Donna Haraway (1997): "Stories and facts do not naturally keep a respectable distance; indeed, they promiscuously cohabit the same very material places" (p. 68). In Chalabi's Instagram posts, it is not only stories and facts that occupy the same space, but also people: the storyteller, the Instagram commenter, the person who contributes even a single statistic to a dataset - they, too, have a role to play.

\section{References}

Aiello, G. (2020). Inventorizing, situating, transforming: Social semiotics and data visualization. In Engrebretsen, M. \& Kennedy, H. (Eds.), Data visualization in society (pp. 49-62). Amsterdam University Press.

Bucher, J., \& Weller, A. (2019). From the visual turn to turned up visuality: Modes of interaction in the digitalized era and ways to utilize them. In Z. Fields, J. Bucher, \& A. Weller (Eds.), Imagination, creativity, and responsible management in the fourth industrial revolution (pp. 80-101). IGI Global.

Burn, A., \& Kress, G. (2018). Multimodality, style, and the aesthetic. In E. S. Tønnessen \& F. Forsgren (Eds.), Multimodality and aesthetics (pp. 15-36). https://doi-org.myaccess.library.utoronto.ca/10.4324/9781315102665

Cantón-Correa, J. (2020). Data visualisation and the modern imagination. Mosaic, 1(187), 16963296. https://doi.org/10.7238/m.n187.2039

Cara, M. (2019). The semiotic layers of Instagram: Visual tropes and brand meaning. The American Journal of Semiotics, 34(3-4), 331-52. https://doi .org/10.5840/ajs201931146

Chalabi, M. [@monachalabi]. (n.d.) Posts [Instagram profile]. Instagram. Retrieved January 26, 2021, from https://www.instagram.com/monachalabi

Chalabi, M. [@monachalabi]. (2020, February 27). Counting the population is hard. There are two main ways you can get it wrong - you can accidentally count some [Photograph]. Instagram. https://www.instagram.com/p/B9FDHFxFKrB

Chalabi, M. [@monachalabi]. (2020, May 30). No justice. No peace. One of the men 4 men who killed George Floyd has been charged with third-degree murder [Photograph]. Instagram. https:// www.instagram.com/p/CAz86y0FYqM 
Chalabi, M. [@monachalabi]. (2020, June 1).BUY BLACK. Your protests and donations are crucial right now but so is long-term economic change. This is a resource [Photograph]. Instagram. https://www.instagram.com/p/CA5T1fW15yW

Chalabi, M. [@monachalabi]. (2020, June 5).I'm British. I have to talk about the British criminal justice system, not least because so many non-black Brits continue [Photograph]. Instagram. https://www.instagram.com/p/CBD2lnO110W

Chalabi, M. [@monachalabi]. (2020, September 22). It did not have to be this way. Sources:Terrorism reported by the Anti-defamation league in 2019, murders reported by [Photograph]. Instagram. https://www.instagram.com/p/CFckc3QlanS

Engebretsen, M., \& Weber, W. (2017). Graphic modes: The visual representation of data. In C. Cotter \& D. Perrin (Eds.), The Routledge handbook of language and media (pp. 277-95). https:// doi.org/10.4324/9781315673134

Gagne, Y. (2020, October 21). To tell the real story, data journalist Mona Chalabi draws imperfect lines. Fast Company. https://www.fastcompany.com/90560856/to-tell-the-real-story-data-journalist-mona-chalabi-draws-imperfect-lines

Gray, J., Chambers, L., \& Bounegru, L. (2012). Why is data journalism important?. In J. Gray, L. Bounegru \& L. Chambers (Eds.), The data journalism handbook: How journalists can use data to improve the news (pp. 3-10). O'Reilly Media Inc.

Haraway, D. (1988). Situated knowledges: The science question in feminism and the privilege of partial perspective. Feminist Studies, 14(3), 575-99. http://www.jstor.org/stable/3178066

Haraway, D.(1997).Modest_Witness@Second_Millennium.FemaleMan_Meets_OncoMouse: Feminism and technoscience. Routledge.

Jaggar, A.M. (1989). Love and knowledge: Emotion in feminist epistemology. Inquiry, 32(2), 15176. http://dx.doi.org/10.1080/00201748908602185

Kennedy, H., \& Engrebretsen, M. (2020). Introduction: The relationships between graphs, charts, maps and meanings, feelings, engagements. In Engrebretsen, M. \& Kennedy, H. (Eds.), Data visualization in society (pp. 19-34). Amsterdam University Press.

Knight, M. (2015). Data journalism in the UK: A preliminary analysis of form and content. Journalism of Media Practice, 16(1), 55-72. http://dx.doi.org/10.1080/14682753.2015.1015801

Leaver, T., Highfield, T., \& Abidin, C. (2020). Instagram: Visual social media cultures. John Wiley \& Sons.

Lewis, S. C., Holton, A. E., \& Coddington, M. (2013). Reciprocal journalism: A concept of mutuiJournal, Vol 6, No. 2, 
al exchange between journalists and audiences. Journalism Practice, 8(2), 229-41. https://doi.org/ $\underline{10.1080 / 17512786.2013 .859840}$

Maitland, H. (2020, November 4). Data journalist Mona Chalabi is trying to piss you off. Vogue. https://www.vogue.co.uk/arts-and-lifestyle/article/mona-chalabi-interview

Manovich, L. (2017). Instagram and contemporary image. Manovich.net. http://manovich.net/index.php/projects/instagram-and-contemporary-image

Pinney, L. (2020). Is literacy what we need in an unequal data society?. In Engrebretsen, M. \& Kennedy, H. (Eds.), Data visualization in society (pp. 223-238). Amsterdam University Press.

Rettberg, J. W. (2020). Ways of knowing with data visualizations. In Engrebretsen, M. \& Kennedy, H. (Eds.), Data visualization in society (pp. 35-48). Amsterdam University Press.

Spencer, S. (2011). Visual research methods in the social sciences. Routledge.

Veglis, A., \& Charalampos, B. (2017). Towards a taxonomy of data journalism. Journal of Media Critiques, 3(11), 109-21. doi:10.17349/jmc117309 